\title{
ORGANIZAÇÕES EM REDE, ECOSSISTEMAS CRIATIVOS E DESIGN ESTRATÉGICO PARA PRODUZIR INOVAÇÃO
}

Felipe Kanarek Brunel

UNISINOS

felipekanarek@gmail.com

Resumo: As organizações em rede surgem como respostas aos desafios e oportunidades da Sociedade em Rede, à medida que o mundo está cada vez mais conectado às redes globais. O Slow Food é um exemplo de organização que se estrutura em rede, voltada a promover o alimento bom, limpo e justo. Nesse caso, a organização emerge da relação entre os objetivos autônomos dos diversos atores em rede. O contexto da Sociedade em Rede também implica transformações às operações de design. De modo que o design estratégico, como processo criativo ecossistêmico de design, torna-se abordagem apropriada para lidar com processos coletivos que se dão em rede. Assim, o objetivo deste artigo é buscar aproximações entre as organizações em rede e os ecossistemas criativos a partir das teorias sobre a complexidade. Visando propor de que forma as operações de design podem tornar-se mais significativas para produzir inovação, quando lidam com o contexto das organizações em rede. Alguns resultados, ainda que parciais, apontam para as operações de design que visam perturbar o ecossistema criativo, afastando-o do equilíbrio para uma zona dialógica entre o caos e a ordem que permite à organização em rede inovar.

Palavras-chave: design estratégico, organização em rede, ecossistema criativo, complexidade, inovação.

Abstract: The network organizations emerge as responses to the challenges and opportunities of the Networked Society, in that the world is increasingly connected global networks. Slow Food is an example of networked structured organization, in order to promote the good, clean and fair food. In these cases, the organization emerges from the relation between the autonomous objectives of the various network actors. The context of the Network Society also implies changes to the pratices of design. So the strategic design, as ecosystem creative process of design, it is appropriate approach to dealing with the collective processes which occur in the network. The purpose of this article is to look for similarities between the organizations networking and creative ecosystems from theories of complexity. In order to propose how the design operations can become more significant to produce innovation when dealing with the context of network organizations. Some results, even partial ones, point to the design 
operations to disrupt the creative ecosystem, away from the balance to a dialogic area between chaos and order that allows the network organization innovate.

Keywords: strategic design, network organization, creative ecosystem, complexity, innovation.

\section{INTRODUÇÃO}

Nas últimas décadas, o mundo vem presenciando uma profunda mudança, comparável às revoluções de outrora, mas que encontram agora nas novas tecnologias da informação um aliado significativo cujas propostas estão "remodelando as bases materiais da sociedade em ritmo acelerado" (CASTELLS, 1999:21). Trata-se de uma nova era, a da sociedade informacional, que Castells trata como Sociedade em Rede. Daí decorre que o mundo está cada vez mais integrado em redes globais como a Internet. Nesse cenário, as organizações sociais têm buscado remodelar-se para responder aos desafios e oportunidades que estão ligados à rede. Essas são denominadas Organizações em Rede por Castells (1999).

O Slow Food, por exemplo, é uma organização não-governamental internacional que se estrutura em rede, por meio do trabalho de mais de uma centena de milhares de associados autônomos, os quais organizam-se em grupos locais para promover o alimento bom, limpo e justo.

O contexto da Sociedade em Rede implica transformações também às operações de design. De modo que a abordagem do design estratégico torna-se apropriada para lidar com as relações ecossistêmicas que se estabelecem em rede. Segundo o Grupo de Pesquisa Design Estratégico para a Inovação Cultural e Social, vinculado ao mestrado em Design da UNISINOS, o design estratégico é processo criativo ecossistêmico de design. É portanto um processo coletivo e que se dá em rede.

Esses fatores levam ao objetivo deste artigo, que é o buscar uma aproximação entre os termos da organização em rede e do ecossistema criativo, a partir das teorias sobre a complexidade, para então propor como as operações de design podem tornarse mais significativas no design estratégico.

As bases teóricas que permitem esta aproximação baseiam-se em autores como Castells (1999), sobre organizações em rede e Franzato et al (2014), Manzini (2003), Mauri (1996) e Zurlo (2010), sobre o design estratégico. Em diálogo com os autores Morin (1998), (2007), (2011), Latour (2012), Deleuze e Guattari (2011), Capra (1996), Capra e Luisi (2014) e Prigogine (1998), os quais permitem refletir sobre as relações ecossistêmicas que se estabelecem em uma organização em rede.

Desses estudos, decorrem que os termos podem ser aproximados aos dos sistemas vivos, as organizações em redes do mundo biológico. De modo que permite ver que as operações de design mais significativas para produzir inovação estão relacionadas à produção de efeitos de sentido que permitam perturbar o ecossistema criativo, afastando do equilíbrio, para que este responda com inovação. 


\section{DESENVOLVIMENTO}

A era da Sociedade em Rede, vista na introdução deste artigo, impõe às organizações novas condições de sobrevivência. Nesse contexto, de novas tecnologias do ciberespaço, o conhecimento torna-se difuso e distribuído. Por isso é compreensível que as organizações remodelem-se em busca de adaptação. Lévy (2014) afirma que as empresas tendem a se organizar em redes de inovação, onde diferentes corporações e setores se conectam e trocam informações e aprendizados.

As redes permitem às organizações gerar e processar informações de forma eficiente, ser flexível e suficientemente abertas às transformações sociais, culturais, tecnológicas e institucionais que as cercam. Sobretudo, as redes permitem inovar de modo que torne a empresa competitiva. Castells (1999) é enfático ao afirmar que são essas as organizações mais bem sucedidas no contexto da sociedade em rede. Dessa forma, as redes tornam-se o sistema operacional deste contexto. Estar em rede é determinante para o sucesso, mas, mais que isso, para a sobrevivência das organizações. Isso porque se dentro da rede as oportunidades são constantes, fora dela se tornam cada vez mais escassas. Em resposta, novas formas organizacionais surgem com as características desta, nova era na qual Castells denomina "empresas em rede" ou organizações em rede.

Organização, na definição de Castells (1999:191), é "um sistema de meios estruturados com o propósito de alcançar objetivos específicos". Nas organizações, diferente de burocracias, a estrutura de meios é modelada e remodelada de forma infinita pelos objetivos que são dinâmicos e mudam constantemente. A organização não é estática, tampouco deve ser confundida com instituições. $O$ autor traz uma definição para organizações em rede:

\footnotetext{
Aquela forma específica cujo sistema de meios é constituído pela intersecção de segmentos de sistemas autônomos de objetivos. Assim, os componentes da rede, tanto são autônomos quanto dependentes em relação à rede e podem ser uma parte de outras redes e, portanto, de outros sistemas de meios destinados a outros objetivos. (CASTELLS, 1999:192)
}

Para tanto, o desempenho da rede depende de dois atributos fundamentais: conectividade - capacidade estrutural que torna possível a comunicação entre os atores da rede - e coerência - o compartilhamento de interesses em comum entre os objetivos autônomos dos atores em rede.

Para efeito de exemplificação, o Slow Food é uma organização nãogovernamental internacional que tem como missão promover o alimento bom, limpo e justo. A organização Slow Food se constitui em rede e possui colaboradores por todo o mundo. Qualquer pessoa pode tornar-se um associado da organização. Uma vez associado, a pessoa passa a participar de forma direta e ativa dentro de seu Convívio (internacionalmente denominado Convívia ou Convivium) para trazer "à vida a filosofia do Slow Food em suas comunidades e ajudando a mudar o sistema alimentar global" (SLOW FOOD, 2016).

Os Convívios são "as células locais e independentes, que trabalham para defender a cultura alimentar do território, divulgando e pondo em prática a filosofia e os objetivos da associação" (SLOW FOOD, 2015). Independentes, esses grupos de ação local são responsáveis pela maior parte dos eventos e ações (mais de seis mil anuais) 
dessa rede, assim como atuam com autonomia na proposição e organização dessas ações. São também os principais replicadores e articuladores dos objetivos do Slow Food entre os diversos atores, colaboradores e associados. Fazem parte dessa rede atores muito heterogêneos, "chefs, jovens, ativistas, agricultores, pescadores, especialistas e professores" (SLOW FOOD, 2016), que trabalham, de forma coletiva, para promover o alimento bom, limpo e justo.

Os objetivos dos atores que se associam à rede são diferentes e, local ou globalmente, remodelam os objetivos da organização. Por isso, as ações do Slow Food, ainda que orientadas pela sua filosofia, são interpretadas de formas muito variadas. Dessa forma, a organização tem condição de atuar em diferentes frentes, com a flexibilização necessária para lidar com o contexto - social, cultural, tecnológico e institucional - que o cerca.

Para tanto, o Slow Food norteia suas ações em quatro grandes nichos baseados nos objetivos da rede: (1) a defesa da biodiversidade; (2) a rede de Terra Madre; (3) o papel fundamental da África e (4) a educação do gosto e a luta contra os desperdícios alimentares. No entanto, o Slow Food realiza ações muito diversas. As ações de amplitude local, propostas e coordenadas pelos Convívios de forma autônoma, correspondem à maior parte dos trabalhos realizados. Outros projetos, campanhas e eventos de maior porte são coordenados pelos escritórios nacionais e pela sede internacional do Slow Food, que fica na cidade de Bra, na Itália. Assim, é possível analisar as organizações em rede, tais quais a Organização Slow Food, sob a ótica do pensamento complexo.

\subsection{0 pensamento complexo e as organizações em Rede}

Vistos pela complexidade, a organização em rede surge da interação entre os atores heterogêneos, humanos e não humanos. Não pela soma, mas pela atitude relacional dos atores (MORIN, 1998; 2007). Castells (1999) expõe que a organização em rede surge do encontro entre os objetivos autônomos dos diversos atores que se relacionam na rede. Os objetivos se encontram mas nunca se fundem, permanecem juntos somente enquanto compartilham interesses em comum. Dá-se sempre em um processo de associação que não cessa de acontecer (LATOUR, 2012).

Dessa forma, o associado do Slow Food permanece na rede enquanto desejar. Ao se associar, ele não assume qualquer compromisso de permanência. O que determina sua participação na rede está inteiramente relacionado aos seus objetivos com a mesma. Enquanto faz parte da rede do Slow Food, o associado pode também participar de outras redes - de diversos propósitos.

Os objetivos dos atores em rede são como os desejos - múltiplos. É possível afirmar que a rede é composta por uma multiplicidade de desejos, uma vez que os atores se associam por desejos que são próprios e que encontram pontos de interesse comum com outros atores. Os encontros entre desejos não respondem a um objetivo que já está dado, como árvore-raiz, na própria organização. Há sempre um duelo, uma negociação entre desejos em um processo que é rizomático (DELEUZE e GUATTARI, 2011).

As conexões se estabelecem por todos os lados. São sempre resultados de aproximações autônomas e portanto não respondem a hierarquias ou a sucessões binárias. Os atores não estão fixados à organização que formam. Eles têm liberdade para associarem-se, desassociarem-se e reassociarem-se nela ou em outros coletivos. 
De outra forma, não há sequer maneira de eleger um ator mais importante que age sobre a rede. É a rede heterogênea, na sua interminável relação e digladiação de desejos, que convida os atores a agirem (LATOUR, 2012). A organização em rede é, portanto, sempre acêntrica, como rizomas (DELEUZE E GUATTARI, 2011). Se acaso uma força hierárquica se sobrepuser aos objetivos autônomos dos atores da organização em rede, essa vira raiz e passa a corresponder aos modelos tradicionais de empresa.

O Slow Food é coordenado por um Conselho Internacional e orientado por um Comitê Executivo. Todas as nomeações deste comitê são eleitos a cada quatro anos. Eles correspondem ao orgão institucional mais alto do Slow Food. A sede internacional, com o Conselho e o Comitê, é responsável por planejar e promover o desenvolvimento da rede e de alguns projetos mais significativos. No entanto, esses grupos não sobrepõem a autonomia dos Convívios e, sobretudo, aos objetivos dos participantes da rede. Dessa forma, o movimento que se produz dentro da rede é de contínua negociação. As propostas de ações não são obrigações que os Convívios devem assumir, mas indicações e sugestões de ações. Nos Convívios, cada ação se dá, também, a partir de um processo de negociação entre os atores que estão envolvidos. Desta forma, mesmo que a rede se organize de forma hierárquica, as hierarquias não sobrepõem aos objetivos autônomos da rede. (SLOW FOOD, 2016)

Segundo Lévy (2014), a rede permite o aprendizado recíproco, a sinergia das competências, a imaginação e a inteligência coletiva. Mas, se é como rizomas, não age como uma força invisível e homogênea que comanda a ação da organização, e sim como constante processo de negociação entre os atores heterogêneos.

No entanto, a organização em rede, onde indivíduos se conectam, trocam e processam informações e aprendizados gerando conhecimento, são coletivos cognitivos. Constituída na atitude relacional de seus componentes, que são ao mesmo tempo autônomos (ficam enquanto há coerência) e dependentes da conectividade e das relações estabelecidas na rede. São abertas e, por isso, estando em ambiente fora de equilíbrio, com negociações constantes entre os objetivos e desejos dos atores que associam e desassociam continuamente e que permitem a transformação constante dos objetivos da rede, tornam-na flexível e adaptativa ao contexto externo. São também fechados, delimitados pela intersecção dos objetivos que constituem o sistemas de meios, auto-organizados na atitude relacional da rede, onde seus componentes produzem-se e transformam-se continuamente entre si. Estas características permitem uma aproximação conceitual entre as organizações em rede de contexto socio-econômico com as organizações em rede do mundo biológico, os sistemas vivos.

As teorias do pensamento complexo levam à compreensão do sistema vivo como aquele que é cognitivo, fechado em uma rede autopoiética e aberta pela sua estrutura dissipativa (CAPRA, 1996). A organização em rede, dentre elas o Slow Food, vista sob essa ótica, pressupõe (1) um padrão de relações, que é delimitado pela intersecção dos objetivos que formam sua estrutura de meios, dá-se entre os componentes (atores heterogêneos e autônomos) que participam da produção e transformação dos outros componentes, produzindo e transformando a própria rede, que produz e transforma seus componentes continuamente. Caracterizando-se como processo autopoiético, em que a própria rede se auto-organiza e se autoproduz através de suas relações cognitivas; (2) a sua estrutura, dissipativa, formalizada pelos componentes físicos dessa organização (os atores que formam a rede e seus desejos) 
trocam constantemente com o meio ambiente (os contextos socioeconômicos) fluxos de energia, matéria e informações. Tornando as organizações em rede abertas para as transformações de seus objetivos, uma vez que os objetivos dos indivíduos se transformam no fluxo de interações com o ambiente externo - até mesmo na entrada e saída de novos componentes. Caracteriza-se, então, como um ambiente fora do equilíbrio em uma constante ação de negociação, atualização e evolução que torna a organização em rede flexível e adaptativa ao contexto externo; (3) seu processo vital se dá pela cognição, $o$ ato de conhecer proporcionado pelas interações entre os componentes. Se dá de forma autopoiética, e também pelos processos de negociações de objetivos proporcionados pela abertura estrutural.

As qualidades próprias de uma organização em rede emergem da multiplicidade dos desejos autônomos entre os atores heterogêneos que se associam, interagem, relacionam-se e se digladiam. De modo que essas qualidades retroagem sobre os atores da rede alterando-os. Os envolvidos, uma vez transformados, alteram também a organização em rede (MORIN, 1998). Desta forma, a organização em rede nunca cessa de se transformar e transformar seus atores. Não se caracterizam como grupos fixos, tampouco homogêneos, com qualidades intrínsecas. Desse modo, não há possibilidades de compreender uma organização em rede pelas suas qualidades, sempre em transformação. O que interessa é investigar o processo de contínua associação dos atores na rede.

Tendo visto as características da organização em rede, tais quais o Slow Food, assume-se que este contexto impõe um novo cenário às operações de design. O design estratégico, por lidar com ecossistemas criativos, torna-se abordagem apropriada. No entanto, para avançar sobre o tema e compreender de que forma o design pode ser mais significativo no trabalho com organizações em rede, faz-se necessário uma aproximação entre os termos apresentados e os ecossistemas criativos do design estratégico, dando ênfase às relações ecossistêmicas que se desenvolvem.

\subsection{Ecossistemas criativos e design estratégico}

Os diversos autores que abordam o design estratégico reforçam a dimensão mais complexa em que o design se estabelece. Manzini (2003:233), por exemplo, afirma que o "design estratégico, por definição, lida com artefatos complexos. (...) Toda solução e, especialmente, soluções sustentáveis trazem um sistema de relacionamento que lida com novas formas de colaboração entre os vários atores e/ou interessados." O design estratégico lida não mais com artefatos triviais ou máquinas que podem ser controladas, mas com organizações, no projeto coletivo da estratégia (MAURI, 1996) e, portanto, com sujeitos e seus ecossistemas. Por isso, está embrenhado em um universo mais complexo do que o que outrora era compreendido como espaço do design.

O design estratégico, segundo o Grupo de Pesquisa Design Estratégico para a Inovação Cultural e Social, vinculado ao mestrado em Design da UNISINOS, caracterizase como processo criativo ecossistêmico de design. Nesse espaço, o design lida com "a elaboração de estratégias para orientar a ação projetual e, sobretudo, a ação organizacional em direção à inovação e à sustentabilidade" (FRANZATO et al 2014:173). São parte desse ecossistema: designers, empresas, usuários e comunidade, entre outros atores que direta ou indiretamente relacionam-se com o processo. Outrora, os ecossistemas já haviam sido identificados por Normann e Ramirez (1993) 
como constelação de valor. Krippendorf (2006) e, depois, Verganti (2009) já haviam identificado os elementos do ecossistema como, consecutivamente, stakeholders e intérpretes.

O termo ecossistema apareceu primeiro na Ecologia. Para Tansley (1935), o ecossistema é uma parte da biosfera composta por elementos bióticos e abióticos delimitados por uma relação de interdependência. O ecossistema, para esse autor e do ponto de vista ecológico, é a unidade básica da natureza na face da Terra. Podem variar de tamanho, mas são sempre complexas formações de redes entre elementos que interagem em uma determinada área. $O$ ecossistema se torna possível porque, a partir de sua delimitação e a interação entre seus elementos, produz seu próprio equilíbrio. Ao mesmo tempo, o ecossistema se mantém aberto ao interagir com outros. Desse modo, o ecossistema mantém-se sempre fora do equilíbrio, mas a partir da relação entre ordem e desordem, ele se auto-organiza.

O ecossistema criativo, de que fala Franzato et al (2014:171-172), trata-se de um ecossistema sociocultural que é caracterizado "pelo desenvolvimento de processos criativos que resultam em dispositivos sócio-técnicos (artefatos, processos ou sistema), possivelmente originais e inovadores". O processo do design estratégico é, portanto, coletivo e se dá em rede. A rede, no entanto, é formada pelos ativos humanos, sujeitos, e os ativos não-humanos. As relações estabelecem-se na interação entre sujeitos, instituições, artefatos, comunidade, mercado e demais atores.

Nos termos apresentados, é possível uma aproximação conceitual entre o ecossistemas criativos e as organizações em rede. Para esta pesquisa, admite-se que ecossistemas criativos podem ser relacionados ao ecossistemas naturais e, desta forma, as organizações em rede do mundo biológico. Assume-se que, nesse sentido, os ecossistemas criativos podem também ser vistos como sistemas vivos. Para Capra (1996), os sistemas vivos são redes de relações, em que o todo se dá nas interações e relações entre os componentes, e não na soma entre eles. Portanto, as relações ecossistêmicas devem ser vistos sobre a ótica da complexidade, que entende o todo como algo que é mais que a soma de suas partes (ARDOINO, 1998) (MORIN, 1998; 2007).

A complexidade permite que o design estratégico seja visto como a consequência de uma complexa rede de relações que faz emergir qualidades próprias que não estão nas partes quando elas estão separadas. Dessa forma, o que diferencia um organismo, o ecossistema criativo e a organização em rede, de outro é a organização das partes e não as partes - que são por si substâncias e materiais que podem ser comuns a diversos organismos (MORIN, 2007) (CAPRA e LUISI, 2014). As emergências produzidas pela rede retroagem sobre o todo e não podem ser percebidas quando as partes estão separadas. Assim, a organização dos atores no ecossistema criativo, produzidos no embate e diálogo entre eles, faz emergir as características de uma dada organização.

O processo de emergência dá-se na relação dialógica entre a ordem e a desordem, entre as atividades de fechamento e abertura. De modo que, diferente de uma máquina trivial, o ecossistema criativo, assim como qualquer outra organização em rede, não pode ser controlado. Capra e Luisi (2014) afirmam que somente há a possibilidade de perturbar o sistema vivo, que reage a sua maneira aos impulsos crises, caos, incertezas - transformando-os em novas qualidades. São as perturbações que deslocam o sistema do equilíbrio para o não-equilíbrio. Segundo Brasset e 
Marenko (2015), citando Stuartt Kauffman, é neste complexo espaço entre a ordem e a desordem que a criatividade se manifesta. Assim, o ecossistema torna-se mais ou menos criativo, mais propenso ou não à inovação, pelas suas capacidades de permanecer aberto às perturbações externas e pela capacidade de responder a essas perturbações.

As organizações do mundo biológico tendem a degradar-se, seja pela ordem degenerativa, seja pela desordem desintegradora. Só é possível refrear esse fim com a regeneração, com a reorganização e com a autoprodução permanente (MORIN, 2011). Da mesma forma ocorre com as organizações em rede e o ecossistema criativo. Esse movimento regenerativo e evolutivo só acontece se a organização, autodelimitada em uma estrutura, mantiver-se em desequilíbrio ordenado. Para Prigogine (1998), isso é possível, porque existem flutuações que conduzem a organização à entropia - a se afastar da ordem - ao mesmo tempo em que o sistema responde - neguentropia - não permitindo a desordem total. Nessa zona fora do equilíbrio, é possível criar, adaptar-se e evoluir. Desse modo, é importante perceber que "estamos num universo do qual não se pode eliminar o acaso, o incerto, a desordem. Nós devemos viver e lidar com a desordem" (MORIN, 2011:89). Nesse sentido, a organização depende tanto da ordem, quanto da desordem.

Para tornar o Slow Food uma organização em rede propícia a produzir inovação de forma local, nos diversos Convívios espalhados pelo mundo, faz-se necessário reconhecer os pontos aqui apresentados. Se não é possível controlar a rede de atores, torna-se mais significativo que as ações voltem-se a deslocá-la para a zona dialógica de não-equilíbrio, ao mesmo tempo em que se busca criar condições dessa se autoorganizar. Uma vez que é a abertura do sistema vivo que permite seu fechamento (MORIN, 2011).

Por fim, é possível afirmar que o ecossistema criativo, de que trata o design estratégico, é uma organização em rede que, a partir de processos criativos, produz de dispositivos sociotécnicos. Por outro lado, as organizações em rede, vistas a partir dos termos do ecossistema, requerem abertura e fechamento para manter-se fora de equilíbrio, em uma zona dialógica entre a ordem e a desordem. Dessa forma, a organização em rede mantém-se em estado criativo e, então, pode produzir inovação. Nesse sentido, o design torna-se estratégico se trabalhar para manter a organização em rede fora de equilíbrio, no estado criativo.

Tendo ciência das complexas relações que se estabelecem dentro de um ecossistema criativo e as aproximações com as organizções em rede, faz-se necessário compreender de que forma as operações de design são mais significativas neste contexto.

\subsection{0 design: elemento perturbador do ecossistema criativo}

Uma vez que o design estratégico opera relações que se estabelecem no ecossistema criativo - tais quais a Organização Slow Food - e, que, portanto, é uma organização que se dá em redes, aproxima-se aos termos de um sistema vivo. Pode-se tirar desses enquadramentos teóricos encaminhamentos para a ressignificação do design estratégico. Franzato et al (2014:174) salienta que, nesse enfoque, o design estratégico "desloca-se do processo de design em si para o conjunto de relações que esses ecossistemas desenvolvem entre si". Essa posição implica questionar o lugar do design. 
Não há qualquer dúvida sobre a importância do design para o processo de design estratégico na geração de efeitos de sentido (ZURLO, 2010). Nesse contexto, o designer opera a partir de suas habilidades, que envolve "uma disposição à intuição e à sensibilidade perceptiva e estética, uma capacidade de escuta e imaginação, de pesquisa da inovação e de recusa pela solução óbvia, que se traduzem em uma única forma: tornar o visível o pensamento" (MAURI, 1996). Para tanto, o design usa as suas capacidades de (1) ver: capacidade de ler os fenômenos para muito além da superfície; (2) prever: a partir do que é visto, antecipar criticamente futuros, e (3) fazer ver: visualizar e tornar visíveis cenários futuros (ZURLO, 2010).

A partir de suas habilidades e capacidade, o designer pode contribuir para tornar visível as estratégias trabalhadas coletivamente e produzir a convergência entre os diversos atores do ecossistema criativo que o cercam. De outro modo, o designer também pode trabalhar na concretização efetiva das estratégias que foram trabalhadas coletivamente em sistemas de oferta, sistemas produto-serviço (ZURLO, 2010). Nesses contextos, o designer atua ajudando o ecossistema a se ordenar.

Em outro sentido, as qualidades do ecossistema criativo do design estratégico emergem das relações em rede que se estabelecem e são peculiares àquela organização. Emergem de uma complexa relação dialógica entre o caos e a ordem. São transdisciplinares (MAURI, 1996), mas, sobretudo, heterogêneas (ARDOINO, 1998) (LATOUR, 2012). Não obstante, a emergência de uma transdisciplinaridade não supõe a constituição de uma unidade de olhares. Tendo em vista que a criatividade se manifesta na complexa relação dialógica entre a ordem e a desordem, a constituição de uma unidade de olhares é ordenadora. Portanto, a ideia de uma visão única pode ser redutora ao processo criativo que se desenvolve no ecossistema. Nesse sentido, o design deve criar as condições para que as multiplicidades não sejam sintetizadas em visões únicas compartilhadas, mas, pelo contrário, deve trabalhar para permitir a produção das multiplicidades, nos termos de Deleuze e Guattari (2011). Para tanto o design estratégico deve operar a partir de estratégias que provoquem o diálogo entre os atores para criarem.

O resultado do processo criativo decorre das interações estabelecidas no ecossistema e responde às perturbações provocadas pelas operações de design. Dessa forma, o design torna-se mais significativo atuando na organização e reorganização das relações criativas estabelecidas no ecossistema (FRANZATO et al, 2014).

Nessa concepção, as operações de design mais significativas dão-se na perturbação do ecossistema para afastá-lo do equilíbrio. De modo que, ao designer, cabe trabalhar para manter abertas as estruturas do sistema ao ambiente externo e às multiplicidades. $O$ ecossistema criativo deve responder às perturbações com inovação.

É na ação projetual que o design estratégico trabalha a instabilidade de seu
ecossistema, traço responsável pela sua constante evolução. Nesse sentido,
a capacidade de leitura e interpretação dos sinais emitidos pelo
ecossistema, aliada à projetação por cenários, é o cerne dos processos de
design, uma vez que permite considerar o regular, o evidente e o possível,
mas também o imprevisível, o acaso, a deriva ou o erro. (FRANZATO et al,
2014:174)

Assim, o designer se desloca de seu papel protagonista na produção da inovação, na qual, a partir de suas habilidades e capacidades, sintetiza as multiplicidades em soluções que respondem ao seu ponto de vista. O design deve 
oferecer os meios para que o ecossistema produza inovação. Para tanto, o designer precisa utilizar de sua capacidade de leitura e interpretação dos sinais externos para produzir efeitos de sentidos, seja no papel de cenários, seja de artefatos, que desloquem o ecossistema para uma zona dialógica entre a ordem e a desordem na qual a criatividade deve manifestar-se.

\section{CONCLUSÃO}

As aproximações entre organizações em rede e ecossistema criativo, tais vistos a partir da complexidade, permitem muitas análises. Seria possível pensar mais especificamente as operações de produção de inovação na organização Slow Food, exposta neste artigo, como exemplo de organização em rede. Mas esse não foi o foco desta pesquisa.

Como visto, em se tratando de organizações em rede, tais quais o exemplo do Slow Food apresentado neste artigo, a produção de inovação se dá como resultado de um processo de diálogo entre os objetivos autônomos dos diferentes autores da rede. Ressalta-se que a abordagem do design estratégico torna-se a mais adequada para esses casos. Assume-se que, nesse contexto, as operações de design se dão de modo que o que interessa é munir o ecossistema de motivos para criar. Através da produção de efeitos de sentido que provoquem o diálogo entre os atores do ecossistema. Esse diálogo é possível na contraposição dos desejos dos atores heterogêneos e não no consenso. Em contrapartida, o designer não controla as reações dos atores do ecossistema criativo e não pode esperar resultados previsíveis.

No entanto, os resultados mais importantes desta pesquisa estão nos desdobramentos que a aproximação dos termos "organizações em rede" $\mathrm{e}$ "ecossistemas criativos" com a teoria da complexidade e os sistemas vivos permitiram às ressignificação do design estratégico.

Desses desdobramentos, o que mais instiga a repensar o design estratégico é assumir que as suas operações mais significativas se dão quando está voltado a perturbar o ecossistema criativo e, dessa forma, permite afastá-lo da ordem para que ele reaja, em uma relação dialógica de caos e ordem, para produzir inovação.

Isso porque pensar em operações de design como perturbadora à ordem do ecossistema criativo requer ir além do papel sintetizador e ordenador dos processos de produção de sentido do design. As multiplicidades devem ser contempladas e produzidas, o que requer repensar os processos de design.

Tendo chegado ao fim deste artigo, é importante ressaltar que os seus resultados são parciais e fazem parte de uma pesquisa que se estende com o objetivo de porpor processos ao design estratégico dentro das ideias que aqui são apresentadas. Portanto, outros temas devem se juntar à pesquisa que está em desenvolvimento, de modo que outras interpretações serão possíveis.

\section{REFERÊNCIAS}

ARDOINO, Jacques. A complexidade. In: MORIN, Edgar. A Religação dos Saberes: 0 desafio do século XXI. 6. ed. Rio de Janeiro: Bertrand Brasil, 2007. p. 548-558.

BRASSET, J. \& MARENKO, B. Deleuze and Design. Edinburgh: Edinburgh Univ. Press, 2015. 
CAPRA, Fritjof. A Teia da Vida: Uma nova compreensão científica dos seres vivos. São Paulo: Cultrix, 1996.

CAPRA, Fritjof; LUISI, Pier Luigi. A visão sistêmica da vida. São Paulo: Cultrix, 2014. 615 p.

CASTELLS, Manuel. A Sociedade em Rede. São Paulo: Paz e Terra, 1999. 617 p.

DELEUZE, G. \& GUATTARI, F. Mil platôs Vol. 1. 2. ed. Rio de Janeiro: Edições 34, 2011.

FRANZATO, Carlo et al. Inovação cultural e social: design estratégico e ecossistemas criativos. In: FREIRE, Karine (Org.) Design Estratégico para a Inovação Social e Cultural. São Paulo: Kazuá, 2015. p. 157-182.

KRIPPENDORFF, Klaus. The semantic turn: a new fundation for design. Boca Raton: Taylor \& Francis, 2006.

LATOUR, Bruno. Reagregando o Social: uma introdução à Teoria do Ator Rede. Salvador: Edufba; Bauru:EDUSC, 2012. 400 p.

LÉVY, Pierre. A Inteligência Coletiva: por uma antropologia do ciberespaço. 9. ed. São Paulo: Edições Loyola, 2014. 214 p.

MANZINI, Ezio. Strategic Design for Sustainability: instruments for radically oriented innovation. In: JÉGOU, F; MANZINI, E. Sustainably everyday: scenarios of urban life. Milano: Edizioni Ambiente, 2003

MAURI, Francesco. Progettare progettando strategia. Milano: Masson S.p.A, 1996 MORIN, Edgar. Complexidade e liberdade. In: MORIN, Edgar; PRIGOGINE, Ilya. A Sociedade em Busca de Valores. Lisboa: Instituto Piaget, 1998. p. 239-254.

MORIN, Edgar. Os desafios da complexidade. In: MORIN, Edgar. A Religação dos Saberes: O desafio do século XXI. 6. ed. Rio de Janeiro: Bertrand Brasil, 2007. p. 559567.

MORIN, Edgar. Introdução ao Pensamento Complexo. 4. ed. Porto Alegre: Sulina, 2011. 120 p.

NORMANN, R.; RAMÍREZ, R. From Value Chain to Value Constellation: Designing Interactive Strategy. Harvard Business Review, n. 71, 1993, p. 65-77.

PRIGOGINE, Ilya. O reencantamento do mundo. In: MORIN, Edgar; PRIGOGINE, Ilya. A Sociedade em Busca de Valores.Lisboa: Instituto Piaget, 1998. p. 229-237.

SLOW FOOD (Brasil). Sobre Nós. Disponível em:

<http://www.slowfoodbrasil.com/imprensa>. Acesso em: 23 jul. 2015.

SLOW FOOD. Rede de Associados. Disponível em:

$<$ http://www.slowfood.com/network/pt-pt/nossa-rede/reseau-de-membres/>. Acesso em: 26 mar. 2016.

TANSLEY, A. G.. The Use and Abuse of Vegetational Concepts and Terms. Ecology, Oxford, v. 16, n. 3, p.284-307, jul. 1935. Disponível em:

<http://www.ecology150anniversary.net/wp-content/uploads/2015/12/tansley1935.pdf>. Acesso em: 26 mar. 2016. 
VERGANTI, Roberto. Design-Driven Innovation: Boston: Harvard Business Press, 2009. $272 \mathrm{p}$.

ZURLO, Francesco. Design Strategico. In: XXI Secolo, vol. IV, Gli spazi e le arti. Roma: Enciclopedia Treccani. 2010. Disponível em:

<http://www.treccani.it/enciclopedia/design-strategico_(XXI-Secolo)/>. Acesso em: 26 ago. 2015. 